\title{
Executive Stock Option Exercises and Inside Information
}

\author{
Jennifer N. Carpenter and Barbara Remmers*
}

November 28, 2000

*Department of Finance, Stern School of Business, New York University, 44 West Fourth Street, New York, NY, 10012, (212)-998-0352 and (212) 998-0365. We thank Yakov Amihud, Brad Barber, Menachem Brenner, Stephen Brown, Philip Dybvig, Edwin Elton, Bruce Grundy, Kose John, Steven Figlewski, Michael Lemmon, Anthony Lynch, Kevin Murphy, Eli Ofek, Matthew Richardson, Nejat Seyhun, Robert Stambaugh, David Yermack, and an anonymous referee for helpful comments and suggestions. We also acknowledge valuable research assistance from Viral Acharya. Please direct correspondence to Jennifer Carpenter (fax: (212) 995-4233, email: jcarpen0@stern.nyu.edu). 


\title{
Executive Stock Option Exercises and Inside Information
}

\begin{abstract}
This paper examines whether corporate insiders use private information to time the exercises of their executive stock options. Prior to May 1991, insiders had to hold the stock they acquired through option exercise for six months. We find that exercises from this regulatory regime precede significantly positive abnormal stock returns. This suggests that insiders timed exercises so that the subsequent forced investment in the stock coincided with favorable price performance. By contrast, we find little evidence of the use of inside information to time exercises since the removal of the holding restriction in May 1991. When insiders can sell the acquired shares immediately, the use of private information should manifest itself as negative abnormal stock price performance following option exercise. However, only in the subsample of exercises by top managers at small firms, a tiny fraction of the full sample, do we find significantly negative post-exercise stock price performance after May 1991. We conclude that, in most cases, insiders' potential information advantage in timing exercises is not an important issue in valuing executive stock options.
\end{abstract}




\section{Introduction}

The debate about the value of executive stock options has focused on features of these options that make them worth less than ordinary options, such as their forfeitability and nontransferability. However, other aspects of these options might enhance their value to the executive. In particular, the executive might have private information about the future price of the underlying stock.

This paper examines whether corporate insiders use private information to time the exercises of their executive stock options. ${ }^{1}$ Our sample includes virtually all reported insider exercises from 1984 to 1990 and from 1992 to 1995. Prior to May 1991, insiders had to hold the stock they acquired through option exercise for six months. ${ }^{2}$ We find that exercises from this regulatory regime precede significantly positive abnormal stock returns. This suggests that insiders timed exercises so that the subsequent forced investment in the stock coincided with favorable price performance.

By contrast, we find little evidence of the use of inside information to time exercises since the removal of the holding restriction in May 1991. When insiders are free to sell the acquired shares immediately, the use of private information should manifest itself as negative abnormal stock price performance following option exercise. However, only in the subsample of exercises by top managers at small firms, a tiny fraction of the full sample, do we find significantly negative post-exercise stock price performance. Otherwise, we find no evidence of exercising on inside information in the current regulatory regime.

\footnotetext{
${ }^{1}$ Section 16(a) of the Securities Exchange Act defines corporate insiders as officers, directors, and beneficial owners of more than $10 \%$ of equity.

${ }^{2}$ In May 1991, the SEC changed the starting date of Section 16(b)'s six-month "short swing" holding period from the exercise date to the grant date of the option. This change effectively eliminated the holding period restriction on shares acquired through exercise, because most option plans already require more than six months between grant and exercise. The SEC also changed the reporting deadline from ten days after the month of the exercise to the sooner of the deadline for the next stock transaction filing or 45 days after the end of the fiscal year of the exercise.
} 
Using data from 1993 to 1995, Ofek and Yermack (2000) find that the typical manager sells virtually all shares acquired through option exercise. However, this by itself is not evidence that insiders exercise options because of private negative information about firm prospects. Exercising and selling could simply reflect diversification or liquidity needs. Detecting the use of private information to time exercises requires an examination of post-exercise stock price performance.

We test for the presence of abnormal stock price performance following insider option exercises using the sample of all exercises from January 1984 to November 1995 that were reported to the SEC by December 1995. The removal of the six-month holding restriction in May 1991 changes the theoretical impact of private information on exercise decisions. Therefore, we separate exercises into two subsamples associated with the different regulatory regimes, those from January 1984 to December 1990, and those from January 1992 to November 1995.

The sample is dominated by large and medium-sized firms, where seasoned option plans are most prevalent. In addition, option exercises tend to take place after large stock price increases. For these reasons, we adjust post-exercise stock returns for both size and momentum before drawing inferences about the use of inside information.

We begin by defining an event at a given firm as a month with any insider exercise. In the pre-1991 subperiod, when the six-month holding period was in effect, abnormal returns in the first six months after an exercise month average a significant 24 basis points per month. However, in the post-1991 subperiod, abnormal returns after insider option exercises are insignificant.

Then we construct subsamples of exercises based on firm size and insider position. We also restrict the sample to include only non-dividend-related exercises or months with a large number of different insiders exercising. In general, the subsample results vary in the direction anticipated. For example, exercises at smaller firms and among higher-ranked insiders seem slightly better timed, that is, they precede higher returns in the pre-1991 subperiod and lower returns post-1991. However, for the most part, 
the results remain qualitatively the same as the full sample: post-exercise abnormal returns are positive in the pre-1991 subperiod and insignificant post-1991. Only when we restrict the sample to top managers at small firms do we find significantly negative abnormal returns in the post-1991 regulatory regime.

We give two reasons for the general non-informativeness of insider exercises in the post-1991 regulatory regime. First, the sample consists almost entirely of large and medium-sized firms, where insiders' informational advantages are likely to be weakest. Indeed, studies of ordinary insider purchases and sales, such as Seyhun $(1986,1998)$ and Lakonishok and Lee (1999), find trades at larger firms to be less informative than trades at smaller firms.

Second, now that insiders can sell the acquired shares immediately, option exercises are like sales in that they are transactions that allow insiders to reduce their exposure to their firms' stock. Given insiders' tendency to accumulate stock and options through compensation, insider sales and exercises may be driven mainly by diversification or liquidity needs. Recent evidence on sales supports this idea. Seyhun (1998) finds that sales are less informative than purchases and that the profitability of sales declined in the 1990s. Lakonishok and Lee (1999) and Jeng, Metrick, and Zeckhauser (2000) find that insider sales are generally not informative at all. Our results suggest that, like sales, option exercises in the current regulatory regime take place primarily for noninformational reasons. We conclude that, except in the case of top managers at small firms, insiders' potential information advantage in timing exercises is not an important issue in valuing executive stock options.

The paper proceeds as follows. Section 2 reviews literature on stock price performance surrounding insider transactions. Section 3 examines the theoretical impact of private information on exercise decisions. Section 4 describes the data and Section 5 describes the methodology. Section 6 presents the empirical results. Section 7 concludes. 


\section{Previous research}

Most studies of stock price performance surrounding insider transactions focus on ordinary purchases and sales of stock. Studies such as Lorie and Niederhoffer (1968), Jaffe (1974), and Seyhun (1986, 1992, 1998) find positive abnormal performance after

purchases and negative abnormal performance after sales. In addition, Seyhun (1986, 1998) finds that insider trades are more profitable the smaller the firm and the closer the insider to top management. More recently, Lakonishok and Lee (1999) and Jeng, Metrick, and Zeckhauser (2000), who control for size and book-to-market effects in measuring abnormal performance, find that insider sales are generally not informative. Lakonishok and Lee (1999) also find that although insider trades at small firms are informative, insider trades at large firms are not.

A few studies of insider trading examine stock price performance surrounding option-related transactions. Seyhun (1998) finds that after insider exercises of call options, returns net of the equal-weighted market portfolio are slightly positive during the period 1975 to 1994 but slightly negative if the sample is restricted to top executive exercises after May 1991. Seyhun (1998) also finds that net stock returns following insider put exercises are significantly positive. Huddart and Lang (1996) find that the fraction of options from a given grant that are exercised in a given month is positively related to prior stock price performance and unrelated to subsequent stock price performance. Yermack (1997) studies option grants and concludes that boards of directors, possibly under influence from CEOs, time grants to top managers so that they precede positive stock price performance.

\section{The impact of information on exercise decisions}

Since May 1991, insiders exercising executive stock options have been free to sell the acquired stock immediately. The main purpose of this section is to establish that in this regime the use of inside information to time exercises should show up empirically 
as negative post-exercise abnormal returns. In particular, we wish to refute a tax-based argument to the contrary.

A call option represents a long position in the underlying stock. If the option holder receives bad news about the future stock price, he may wish to reduce this position. If the option is nontransferable, then exercising the option and selling the acquired stock is the only way to reduce the position. Therefore, private negative information can trigger an exercise.

Some argue on the other hand that if the executive expects the stock price to rise over the coming year, he should exercise and hold the stock, because income from the option payoff is taxed at a higher rate than capital gains on stock holdings. We show that this tax-based argument for exercising prior to positive stock performance is not valid. In particular, if the executive expects the stock price to rise sufficiently, he is better off holding the option and buying additional stock with the money that he would otherwise have to pay to exercise the option, namely, the strike price and the tax on the existing option profit. More precisely, in the Appendix, we prove the following:

Proposition Suppose an executive holding an in-the-money nontransferable option knows the future one-year stock return with certainty. Suppose the executive can exercise the option today or in one year and can also invest in stock and bonds. Finally, suppose the executive chooses an exercise and investment policy to maximize his endof-year payoff. Then there exists a critical value such that, if his stock price forecast is above the critical value, the executive holds the option, and if his forecast is below the critical value, he exercises the option.

The critical value of the stock price forecast, at which the optimal exercise decision changes, depends on the strike price, the interest rate, the dividend rate, and the tax rates. Nevertheless, for any configuration of these parameters, as the future stock price forecast ranges from favorable to unfavorable, the optimal exercise decision switches from holding the option to exercising it. A model of the executive's optimal exercise 
policy with a binomial stock price, available from the authors, delivers the same basic result. The essential implications of the models are:

1. Private bad news about the future stock return may or may not trigger an exercise of a nontransferable option. Small downward revisions in the executive's stock price forecast may not push him into the exercise region, but large ones will.

2. Private good news cannot trigger an exercise. Upward revisions in the executive's forecast can only move him farther from the exercise region.

Statistical tests of insider trading examine abnormal returns, not total returns. Although the models described above do not distinguish between abnormal and total returns, because they do not incorporate multiple risky assets, they still illustrate the essential information effect: private information can trigger an option exercise only if it reduces the insider's desired exposure to the stock. Since an insider's private information is typically specific to his firm, it tends to be information about the stock's abnormal return. Furthermore, portfolio theory indicates that it is news about abnormal return that changes desired holdings. Therefore, the use of inside information to time exercises should show up as negative post-exercise abnormal returns.

Of course, exercises can also take place for reasons unrelated to private information. Insiders' natural long position in their firms through stock-based compensation and human capital should precipitate option exercises and stock sales purely to meet diversification and liquidity needs. Noninformational events such as dividend payments, employment termination, and option expiration can also trigger exercises. Therefore, the average information content of insider option exercises is an empirical question.

\section{Information and exercises prior to May 1991}

Prior to May 1991, the SEC required insiders to hold the stock acquired through exercise for six months. In the presence of this holding restriction, the impact of new information on exercise decisions is not obvious. News suggesting that the stock price 
is entering into a long slow decline might cause the holder of a deep-in-the-money option to exercise in order to get through the holding period and still capture some of the option profit. On the other hand, good news about the future stock return might make an option holder exercise because it makes him more willing to endure the holding period. This latter information effect would generate positive post-exercise stock performance.

\section{Data}

The data set consists of all option exercises by corporate insiders that took place after January 1, 1984 and were reported to the SEC by December 19, 1995. The source of the data is CDA/Investnet. After the removal of duplicate or incomplete filings, there remain 201,003 exercises across 7,560 different firms. We focus on option exercises from two subperiods, before and after the SEC lifted the six-month holding restriction on stock acquired through option exercise. The first subsample contains exercises from January 1984 through December 1990; the second contains exercises from January 1992 through November 1995. We exclude exercises in 1991 to eliminate any temporary effects of the regime change and to obtain statistical independence of results in different regimes.

Our data do not indicate whether the shares acquired through option exercise were held or sold. However, this is not likely to be a problem because Ofek and Yermack (2000) find that in this regime, almost all executives sell the shares acquired through option exercise. In addition, we are unable to eliminate exercises triggered by option expiration because expiration dates are not publicly available in electronic form. Again, however, we do not believe this is a problem. Using proprietary data on option exercises from 1985 to 1995, Huddart and Lang (1996) find that most exercises occur well before expiration.

Figures 1a and 1b plot the number of firms with insider exercises in each month 
of the first and second subperiods, respectively. The figures show that exercise filings are more frequent during the post-1991 regime. This may be because compliance with SEC rules has improved with the new regulation, because option grants have increased over time, or because strong stock market performance put more options in the money. Another possibility is that the holding restriction of the first regime lead more insiders to exercise tandem stock appreciation rights and get the option payoff in cash rather than exercise options outright.

At the monthly level, Figures $1 \mathrm{a}$ and $1 \mathrm{~b}$ show that year-end months tend to be peak exercise times, probably for tax-timing reasons. December 1992 has the greatest number of exercises, reflecting attempts to recognize option income before the tax increase of 1993. In recent years, a quarterly pattern emerges with peaks in February, May, August, and November. This may be associated with the growth in corporate restrictions that limit insider trading to windows of time after quarterly earnings announcements (see Jeng (1998) and Bettis, Coles, and Lemmon (2000)).

Figures 1a and 1b also show the size composition of the sample firms. "Small" firms are those in the bottom three CRSP size deciles, "medium" firms are those in the middle four size deciles, and "large" firms are those in the top three size deciles. The figures show that the sample is heavily weighted towards large and medium-sized firms. In an average month, $67 \%$ of the firms with insider exercises are large, while only $6 \%$ are small. The scarcity of small firms in our sample is consistent with insider trading patterns documented elsewhere. Lakonishok and Lee (1999) find that, although the frequency of ordinary insider purchases is fairly similar across firms of different size, insider sales and option exercises are much more frequent at larger firms. Seyhun (1998) also finds that sell months are more frequent at larger firms. This seems to be because seasoned option compensation plans, which precipitate exercises and sales, are more prevalent at larger firms during this time period. 


\section{Methodology}

To address the question of whether insiders use private information to time their option exercises, we test for the presence of abnormal post-exercise stock price performance. In each subperiod, pre-1991 and post-1991, we examine stock price performance over periods ranging from one day to one year after the exercise. We also ask whether the removal of the holding restriction on acquired stock altered insiders' exercise strategies by testing for a difference in post-exercise stock price performance across the two regulatory regimes.

\subsection{Measuring abnormal performance}

We measure a firm's abnormal return as the deviation of its return from the return on a benchmark portfolio of firms with similar characteristics. Our sample firms are unusual in two respects. First, they are almost all large and medium-sized firms. Second, as we document in Section 6, they experience significant stock price increases prior to the event. We control for both of these characteristics. ${ }^{3}$

We begin by presenting returns adjusted for firm size only, using the CRSP size decile portfolios as benchmarks. Adjusting returns for size is widely used as a method for measuring abnormal performance (see, for example, Desai and Jain (1995), Loughran and Ritter (1995), or Michaely and Womack (1996)). The approach is founded on considerable evidence that firm size is important in explaining cross-sectional differences in expected stock returns (see, for example, Fama and French (1992)) and has formal theoretical justification as well (see Berk (1995)).

\footnotetext{
${ }^{3}$ We also examine the alphas in monthly calendar time series regressions of event portfolio excess returns on the Fama and French (1993) market, size, and book-to-market factors (we thank Ken French for these data). The event portfolio is rebalanced monthly to hold all firms that have had an insider exercise during a specified period of time relative to the rebalancing date. For virtually every post-event period specified, the significance of the portfolio's estimated three-factor alpha is the same as that of its mean size-adjusted return.
} 
However, before we draw inferences about the use of inside information to time exercises, we also control for firms' extraordinary pre-exercise stock price performance. Several papers find a "momentum" effect in stock returns in the time period of this study (see, for example, Jegadeesh and Titman (1993), Fama and French (1996), and Chan, Jegadeesh, and Lakonishok (1996)): over short horizons, stocks that have done well in the past outperform stocks that have done poorly. Lyon, Barber, and Tsai (1999) find that in random samples of firms with good pre-event returns, tests for abnormal performance that do not control for momentum over-reject the null hypothesis of no abnormal post-event performance in favor of positive performance. Therefore, we base our conclusions on size-momentum-adjusted returns using a set of fifty benchmark portfolios of stocks in different size deciles and momentum quintiles. Following Carhart (1997), we define momentum for a firm in month $t$ as its compound return over months $t-12$ through $t-2$.

\section{$5.2 \quad$ Assessing significance}

Option exercises are frequent events, so post-event periods overlap in calendar time. Therefore, a cross-sectional t-statistic that treats the post-event abnormal returns as independent is inappropriate. Instead, we assess statistical significance using the calendar time portfolio method recommended by Lyon, Barber, and Tsai (1999). Jaffe (1974), Mandelker (1974), and more recently, Loughran and Ritter (1995), Brav and Gompers (1997), and Mitchell and Stafford (1997) all use variations of this approach.

For any given event period of interest, we create a calendar time series of the average abnormal return on a portfolio of the firms that are in the specified event period. For example, if the period of interest is months 1 through 6 of event time, then each calendar month, the event portfolio contains all firms with an option exercise in the preceding six calendar months. From this calendar time series, we compute the mean abnormal return, its standard error, and a t-statistic. ${ }^{4}$

\footnotetext{
${ }^{4}$ One concern with this approach is the possibility that, because the number of firms in the event
} 


\section{Results}

We begin by analyzing abnormal performance surrounding exercise events using the full sample of option exercises in Section 6.1. Then we examine post-exercise performance for various subsamples in Section 6.2. Section 6.3 discusses the results.

\subsection{Results for the full sample}

We present returns adjusted for size in Section 6.1.1 and for both size and momentum in Section 6.1.2. Each section starts by examining stock performance over long event periods, with an event at a given firm defined as a month with at least one insider exercise. Then we look at performance in the days immediately surrounding exercises, defining an event as a day with an insider exercise.

\subsubsection{Returns adjusted for size}

Table 1 and Figure 2 describe stock price performance over the years surrounding the exercise month. For each of the two regulatory regimes, Table 1 reports mean monthly size-adjusted returns and t-statistics for months -12 to 12 . Figure 2 plots the cumulative average monthly size-adjusted return from month -120 to 12 .

Prior to option exercises, stock prices rise dramatically. Size-adjusted returns in the year before an exercise month average 1\% per month during the pre-1991 subperiod and $1.6 \%$ per month during the post-1991 subperiod. The t-statistics for each of months -12 to -1 range from 7.58 to 15.62 . Table 1 also shows the t-statistics for differences

portfolio changes over time, the portfolio abnormal returns are heteroskedastic. To address this concern, we regress the squared residuals on the number of firms in the event portfolio, a diagnostic used by Mitchell and Stafford (1997), and on the inverse of the number of firms in the event portfolio. In the monthly time series for the full sample and for most of the subsamples, we find no relation. In the remaining cases, we do find that residuals of smaller portfolios have higher variance, but when we correct for this by reweighting the abnormal returns based on their estimated variance, the results are virtually the same. 
in regime means. The pre-exercise abnormal returns are significantly higher in the post-1991 regime than in the pre-1991 regime.

That exercises tend to take place after strong stock price performance is not surpris-

ing. It is consistent with insiders following an exercise policy that calls for exercising once the stock price rises sufficiently high and does not provide any evidence regarding the use of private information. Testing for private information trading involves examining stock price performance after the option exercise.

After option exercise, size-adjusted stock returns diminish substantially, but remain positive. In the pre-1991 subperiod, when the six-month holding restriction on acquired shares was in effect, the mean monthly abnormal return for event months 1 through 6 is 35 basis points with a t-statistic of 3.39. In months 7 through 12, after the holding period expires, the mean abnormal return falls to 18 basis points per month, with a t-statistic of 1.73. In the post-1991 subperiod, which has no holding restriction, mean size-adjusted returns after exercises are positive but smaller. Only in month 1 is the mean abnormal return significant, 31 basis points with a t-statistic of 2.18.

Table 2 and Figure 3 describe stock price performance over the trading 40 days surrounding the exercise day. The daily stock return pattern is similar to the monthly: a striking run-up prior to exercise, especially in the second regime, that flattens out after exercise. Prior to the exercise, the average daily abnormal stock return reaches 13 basis points on day -1 in the pre-1991 subperiod, and 30 basis points on day -1 in the post-1991 subperiod. Again, pre-exercise abnormal returns in the post-1991 subperiod are significantly higher than in the pre-1991 subperiod. After the option exercise, sizeadjusted returns remain significantly positive, an average of 4 basis points per day in the twenty days after the exercise day.

\subsubsection{Returns adjusted for size and momentum}

With such strong pre-exercise stock price performance, controlling for a momentum effect in post-exercise performance is imperative. The control is especially important 
for the post-1991 subperiod where the pre-exercise performance is stronger. Table 3 presents monthly returns adjusted for both size and momentum in the year after an exercise month. Table 4 presents daily size-momentum-adjusted returns in the 20 days after an exercise day.

Controlling for momentum generally reduces the magnitudes of the abnormal returns, but in the pre-1991 regulatory regime they remain significantly positive. For example, in the pre-1991 subperiod, the average abnormal return in months 1 to 6 falls from 35 to 24 basis points per month but is still significant with a t-statistic of 2.88 . The average abnormal return in days 1 to 20 falls from 4 to 2 basis points per day but is still significant with a t-statistic of 5.14.

In the post-1991 regulatory regime, however, controlling for momentum removes virtually all positive abnormal performance of firms after an option exercise. Using the size-momentum benchmarks reduces the mean month 1 abnormal return in the post-1991 subperiod from 31 to 13 basis points and the corresponding t-statistic from 2.18 to 1.21 . The mean daily return for days 1 to 20 falls from 4 to 1 basis point per day and its t-statistic falls from 4.64 to 1.01 .

\subsection{Results for various subsamples}

The full sample results suggest that in the pre-1991 regulatory regime, insiders used private information to time option exercises so that the resulting six-month investment in the underlying shares coincided with a period of favorable stock price performance. However, the post-1991 results for the full sample provide no evidence that insiders use private information to exercise in advance of poor stock price performance now that they are free to sell the underlying shares immediately. To investigate this finding, this section studies subsamples designed to isolate option exercises most likely to reflect the use of private information. First we examine subsamples of exercises grouped by firm size or insider position. Then we restrict the sample to non-dividend-related exercises. Finally, we look at firm months with widespread exercising. The remainder of this 
section describes each subsample and Table 5 contains the main results.

\subsubsection{Subsamples based on firm size}

Insider trading may be more profitable at smaller firms where the information asymmetry between insiders and outsiders may be greater and where a given piece of information may have greater impact on the market value of the firm as a whole. Studies of ordinary insider stock purchases and sales, such as Seyhun $(1986,1998)$ and Lakonishok and Lee (1999), find that insider trading is more informative at smaller firms. Rows 2,3 , and 4 of Table 5 present average monthly size-momentum-adjusted returns in the six months following an insider exercise for small, medium-sized, and large firms, respectively. The results vary with firm size in the direction anticipated: smaller firms have higher post-exercise abnormal returns than larger firms in the pre-1991 regulatory regime and lower post-exercise returns in the post-1991 regime. However, the results are qualitatively the same as in the full sample. Abnormal returns are significantly positive in the old regime and insignificant in the new.

\subsubsection{Subsamples based on insider position}

Higher-ranked insiders might have better information about the prospects of the firm. For instance, Seyhun (1998) finds that ordinary stock sales and purchases by top executives are more profitable than those of other insiders. Rows 5, 6, 7, and 8 of Table 5 present post-exercise abnormal returns for four classes of insiders: top managers, defined as firm presidents and board chairmen, officers, directors who are not also officers, and large shareholders who are not also officers or directors. Again, the results vary with insider position in the way we might expect: exercises by higher-ranked insiders precede higher abnormal returns in the pre-1991 subperiod and lower abnormal returns in the post-1991 subperiod. Unlike the pre-1991 results for the full sample, the pre-1991 post-exercise abnormal returns for large shareholders are insignificantly different from zero. Otherwise, however, the results remain qualitatively the same as 
those for the full sample. In particular, even top manager exercises do not precede significantly negative abnormal returns in the post-1991 subperiod.

\subsubsection{Exercises by top managers at small firms}

Next, we examine size-momentum-adjusted returns in the six months following an insider exercise for all twelve firm size-insider position subsamples. For all but one subsample, the abnormal returns in the post-1991 regime are insignificant. In the small firm-top manager subsample, however, the results are dramatic. This is exactly where we would expect to see the largest post-exercise abnormal returns, because this is where insiders' information advantage is likely to be greatest, and the evidence confirms this prediction. As row 9 of Table 5 shows, in the six months after these exercises, mean abnormal returns are 120 basis points per month during the pre-1991 subperiod and -87 basis points during the post-1991 subperiod. The negative mean abnormal return in the post-1991 subperiod is significant, with a t-statistic of -2.45.

\subsubsection{Non-dividend-related exercises}

One noninformational reason to exercise an option early is to capture the value of a dividend. We define non-dividend-related exercises as those which do not fall between a dividend announcement date and an ex-dividend date. Row 10 of Table 5 describes abnormal returns following months with at least one non-dividend-related exercise. The results are virtually the same as those for the full sample. We also find that restricting the firm size-insider position subsamples to non-dividend related exercises has little effect.

\subsubsection{Months with many insiders exercising}

Private information about firm prospects could be a reason for widespread exercising, as opposed reasons such as liquidity needs which might be independent across different executives. This subsample includes only firm months in which the number of different 
insiders exercising is unusually high. Different firms have different numbers of insiders and option programs of varying depths. In identifying a month with intense activity at a given firm we wish to take into account the normal level for that firm as well as seasonal patterns in the data. We use a simple approach. We first eliminate December and January exercises, many of which may be motivated by tax timing. For each remaining month, we compare the number of different insiders exercising to the average number of insiders exercising in each of the three previous months on the same quarterly cycle. If the number of insiders exercising in a given month exceeds the past average, that month is classified as having high activity, or widespread exercising. The results for these high activity months appear in Row 11 of Table 5. Again, the restriction makes a difference in the direction anticipated, but the effect is slight. Post-exercise excess returns in the second regime remain insignificantly different from zero.

\subsection{Discussion}

Requirements to hold stock for six months after option exercise appear to have lead insiders to time option exercises so that they preceded favorable stock price performance. In the pre-1991 subperiod, size-momentum-adjusted returns over the six months after exercise are significantly positive for the full sample and most of the subsamples. They are also greater than the corresponding post-1991 returns at marginal significance levels in the full sample and at conventional significance levels in the small-firm and higher-ranked-insider subsamples.

The results do not however indicate a pervasive use of inside information to time exercises now that insiders are free to sell acquired shares immediately. When immediate stock sale is possible, call option exercises are like sales in the sense that they are transactions that allow an insider to reduce his exposure to the firm's stock return. For

this reason, the use of private information should manifest itself as negative abnormal stock price performance after exercises. Yet only in the subsample of exercises by top managers at small firms, a tiny fraction of the full sample, are size-momentum-adjusted 
returns significantly negative in the post-1991 subperiod.

The general non-informativeness of exercises during the period 1992 to 1995 may seem somewhat puzzling given that numerous studies find ordinary insider transactions to be abnormally profitable. However, the result is not entirely surprising given the striking size composition of the sample. The sample consists almost entirely of large and medium-sized firms where studies of ordinary purchases and sales find insider trades to be the least informative.

The general absence of negative stock price performance following insider exercises from the post-1991 subperiod is also consistent with recent evidence on insider sales. Insiders accumulate large holdings of stock and call options through their compensation. Therefore, option exercise and sales may be driven mainly by liquidity and portfolio rebalancing needs unrelated to private information. Lakonishok and Lee (1999) and Jeng, Metrick, and Zeckhauser (2000) find that insider sales are generally not informative. Our evidence suggests that, like sales, option exercises take place primarily for noninformational reasons. Only where the insider's information advantage is greatest do we find evidence of trading on inside information.

\section{Conclusion}

This paper studies the information content of insider option exercises. Prior to May 1991, the SEC required insiders to hold acquired shares for six months after option exercise. We find that exercises from 1984 to 1990 precede significantly positive abnormal returns. This suggests that when exercising an option entailed a mandatory six month investment in the stock, insiders used private information to exercise before good stock price performance.

In May 1991, the SEC removed the holding period restriction. We show that if the executive can sell the acquired shares immediately after exercise, bad news can trigger an option exercise but good news cannot, even when income tax rates exceed capital 
gains tax rates. This implies that after May 1991, the use of private information should manifest itself as negative post-exercise abnormal performance.

Empirically, we find that during the period 1992 to 1995, abnormal returns after exercises by top managers at small firms are significantly negative. Otherwise, however, we find no evidence of the use of inside information to time option exercises. We offer two reasons for this general non-informativeness of insider exercises. First, the sample consists almost entirely of large and medium-sized firms, where insiders' information advantages are the weakest. Second, now that insiders can sell the acquired shares immediately, exercises are like sales, which appear to take place primarily for diversification and liquidity purposes unrelated to private information.

Our results suggest that compensation committees at small firms granting options to top managers may wish to take into account the possibility that informational advantages increase the value of the options to the managers. In most cases, however, asymmetric information does not appear to be an important concern for the valuation of executive stock options.

\section{Appendix: Proof of proposition}

Without loss of generality, assume that the current stock price is one and the executive has just one option. Let

$$
\begin{aligned}
k & =\text { strike price of the options, } 0<k<1, \\
\tau_{i} & =\text { income tax rate, } 0 \leq \tau_{i}<1 \\
\tau_{c} & =\text { capital gains tax rate, } 0 \leq \tau_{c}<1 \\
\hat{r} & =\text { after-tax interest rate, } \hat{r}>0 \\
\hat{\delta} & =\text { after-tax dividend rate, } \hat{\delta} \geq 0 \text { and } \\
1+r_{s} & =\text { future stock price. }
\end{aligned}
$$


For example, if interest and dividends are taxable as income, then $\hat{r}=r\left(1-\tau_{i}\right)$ and $\hat{\delta}=\delta\left(1-\tau_{i}\right)$ where $r$ and $\delta$ are the pre-tax interest rate and dividend rate.

If the executive exercises the option today, he gets $\left(1-\tau_{i}\right)(1-k)$ after taxes. If he waits until the end of the year, he will get $\left(1-\tau_{i}\right)\left(1+r_{s}-k\right)^{+}$. The implied after-tax rate of return from leaving the option alive, instead of exercising it, is

$$
\begin{aligned}
\text { after-tax option return } & =\frac{\left(1-\tau_{i}\right)\left(1+r_{s}-k\right)^{+}}{\left(1-\tau_{i}\right)(1-k)}-1 \\
& =\max \left(\frac{r_{s}}{1-k},-1\right)
\end{aligned}
$$

Compare this to the after-tax returns of the stock and the bond. The after-tax bond return is $\hat{r}$. The after-tax stock return is $r_{s}\left(1-\tau_{c}\right)+\hat{\delta}$. We assume for expositional purposes that the capital gains tax applies symmetrically to gains and losses. The result is the same if the capital gains tax applies only to positive gains.

The executive chooses to exercise the option or not according to which action maximizes his future payoff. If the after-tax option return exceeds both the stock and bond returns then leaving the option alive yields the greatest future payoff. If the return on either the stock or the bond exceeds the option return, then the executive's best strategy is to exercise the option and invest the after-tax profit in the asset with the greater return. The question of which return is greatest depends on the level of the future stock price. It also depends on the values of the other parameters. Let

$$
\begin{aligned}
b_{1} & \equiv \frac{\hat{\delta}(1-k)}{\tau_{c}(1-k)+k}, \\
b_{2} & \equiv \hat{r}(1-k), \\
b_{3} & \equiv \frac{\hat{r}-\hat{\delta}}{1-\tau_{c}} .
\end{aligned}
$$

If $r_{s}>b_{1}$, the option return exceeds the stock return. If $r_{s}>b_{2}$, the option return exceeds the bond return. If $r_{s}>b_{3}$, the stock return exceeds the bond return. These relations imply that the following exercise and investment policy is optimal: 
(i) Low dividend: If $\hat{\delta} \leq \hat{r}\left(k\left(1-\tau_{c}\right)+\tau_{c}\right)$, then $b_{1} \leq b_{2} \leq b_{3}$ and the optimal policy is

$$
\begin{array}{r}
\text { Exercise option \& Invest in bonds } \text { if } r_{s}<b_{2}, \\
\text { Leave option alive if } r_{s} \geq b_{2} .
\end{array}
$$

(ii) High dividend: If $\hat{\delta}>\hat{r}\left(k\left(1-\tau_{c}\right)+\tau_{c}\right)$, then $b_{1}>b_{2}>b_{3}$ and the optimal policy is

$$
\begin{aligned}
\text { Exercise option \& Invest in bonds } & \text { if } r_{s}<b_{3}, \\
\text { Exercise option \& Invest in stock } & \text { if } \quad b_{3} \leq r_{s}<b_{1}, \\
\text { Leave option alive } & \text { if } \quad r_{s} \geq b_{1} .
\end{aligned}
$$

In both configurations of the parameters $\hat{\delta}, \hat{r}, k$, and $\tau_{c}$, the optimal exercise policy involves exercising only when the anticipated stock price $1+r_{s}$ lies below some critical level. 


\section{References}

Berk, Jonathan B., 1995, A critique of size-related anomalies, Review of Financial Studies 8, 275-286.

Bettis, J. Carr, Jeffrey L. Coles, and Michael L. Lemmon, 2000, Corporate policies restricting trading by insiders, Journal of Financial Economics, 57, 191-220.

Brav, Alon and Paul A. Gompers, 1997, Myth or reality? The long-run underperformance of initial public offerings: Evidence from venture and nonventure capitalbacked companies, Journal of Finance forthcoming.

Carhart, Mark M., 1997, On persistence in mutual fund performance, Journal of Finance 52, 57-82.

Chan, Louis K. C., Narasimhan Jegadeesh, and Josef Lakonishok, 1996, Momentum strategies, Journal of Finance 51, 1681-1713.

Desai, Hemang and Prem C. Jain, 1995, An analysis of the recommendations of the "superstar" money managers at Barrons annual roundtable, Journal of Finance, $50,1257-1273$.

Fama, Eugene F. and Kenneth R. French, 1992, The cross-section of expected stock returns, Journal of Finance 47, 427-466.

Fama, Eugene F. and Kenneth R. French, 1993, Common risk factors in the returns of stocks and bonds, Journal of Financial Economics 33, 3-56.

Fama, Eugene F. and Kenneth R. French, 1996, Multifactor explanations of asset pricing anomalies, Journal of Finance 51, 55-84.

Huddart, Steven and Mark Lang, 1996, Employee stock option exercises: An empirical analysis, Journal of Accounting and Economics 21, 5-43. 
Jaffe, Jeffrey F., 1974, Special information and insider trading, Journal of Business $47,410-428$.

Jegadeesh, Narasimhan and Sheridan Titman, 1993, Returns to buying winners and selling losers: Implications for stock market efficiency, Journal of Finance 48, 65-91.

Jeng, Leslie A., 1998, Corporate insiders, market makers, and the window of opportunity, working paper, Boston University.

Jeng, Leslie A., Andrew Metrick, and Richard Zeckhauser, 2000, Estimating the returns to insider trading: A performance-evaluation perspective, NBER Working Paper No. W6913.

Lakonishok, Josef, and Inmoo Lee, 1999, Are insiders' trades informative, working paper, University of Illinois at Urbana-Champaign.

Lorie, James H. and Victor Niederhoffer, 1968, Predictive and statistical properties of insider trading, Journal of Law and Economics 11, 35-51.

Loughran, Tim and Jay Ritter, 1995, The new issues puzzle, Journal of Finance 50, $23-52$.

Lyon, John D., Brad M. Barber, and Chih-Ling Tsai, 1999, Improved methods for tests of long-run abnormal stock returns, Journal of Finance 54, 165-201.

Mandelker, Gershon, 1974, Risk and return: The case of merging firms, Journal of Financial Economics 1, 303-335.

Michaely, Roni and Kent L. Womack, 1996, Conflicts of interest and the credibility of underwriters' analysts' recommendations, working paper, Cornell University.

Mitchell, Mark L. and Erik Stafford, 1997, Managerial performance and long-term stock price performance, working paper, University of Chicago. 
Ofek, Eli and David Yermack, 2000, Taking stock: Equity-based compensation and the evolution of managerial ownership, Journal of Finance 55, 1367-1384.

Seyhun, H. Nejat, 1986, Insiders' profits, costs of trading, and market efficiency, Journal of Financial Economics 16, 189-212.

Seyhun, H. Nejat, 1992, The effectiveness of the insider-trading sanctions, Journal of Law and Economics 35, 149-182.

Seyhun, H. Nejat, 1998, Investment Intelligence from Insider Trading, MIT Press.

Yermack, David, 1997, Good timing: CEO stock option awards and company news announcements, Journal of Finance 52, 449-476. 


\section{TABLE 1 Monthly Size-Adjusted Returns Surrounding Insider Option Exercises}

Calendar time series means and t-statistics for monthly size-adjusted returns on event portfolios. An event at a firm is a month in which at least one insider exercises an option. Each event portfolio is rebalanced monthly to hold all firms in the indicated event period. The table summarizes time series from two different regulatory regimes. Prior to May 1991, the SEC required insiders to hold shares acquired through exercise for six months. In May 1991, the SEC removed this restriction.

\begin{tabular}{|c|c|c|c|c|c|}
\hline Event period & $\begin{array}{l}\text { Jan } 1984 \text { tc } \\
\text { Mean (bp) }\end{array}$ & $\begin{array}{l}\text { Dec } 1990 \\
\text { t-statistic }\end{array}$ & $\begin{array}{l}\text { Jan } 1992 \text { to } \\
\text { Mean (bp) }\end{array}$ & $\begin{array}{l}\text { Nov } 1995 \\
\text { t-statistic }\end{array}$ & $\begin{array}{l}\text { t-statistic for difference } \\
\text { in regime means }\end{array}$ \\
\hline Month -12 & 109 & 9.01 & 151 & 8.79 & -2.03 \\
\hline Month -11 & 105 & 7.98 & 154 & 11.00 & -2.53 \\
\hline Month -10 & 97 & 9.50 & 161 & 10.63 & -3.53 \\
\hline Month -9 & 99 & 8.16 & 152 & 10.56 & -2.82 \\
\hline Month -8 & 106 & 9.01 & 141 & 9.28 & -1.80 \\
\hline Month -7 & 108 & 8.84 & 150 & 11.61 & -2.37 \\
\hline Month -6 & 97 & 8.08 & 154 & 11.17 & -3.09 \\
\hline Month -5 & 94 & 8.05 & 149 & 10.96 & -3.08 \\
\hline Month -4 & 101 & 7.58 & 170 & 13.02 & -3.74 \\
\hline Month -3 & 101 & 8.26 & 167 & 10.98 & -3.41 \\
\hline Month -2 & 113 & 9.60 & 183 & 12.82 & -3.81 \\
\hline Month -1 & 130 & 9.66 & 229 & 15.62 & -5.00 \\
\hline Month 0 & 120 & 8.38 & 174 & 10.26 & -2.43 \\
\hline Months 1 to 6 & 35 & 3.39 & 13 & 1.03 & 1.34 \\
\hline Months 7 to 12 & 18 & 1.73 & 17 & 1.40 & 0.06 \\
\hline Month 1 & 48 & 3.59 & 31 & 2.18 & 0.89 \\
\hline Month 2 & 42 & 3.58 & 0 & 0.02 & 2.10 \\
\hline Month 3 & 43 & 3.45 & 9 & 0.65 & 1.82 \\
\hline Month 4 & 34 & 2.51 & 10 & 0.77 & 1.24 \\
\hline Month 5 & 26 & 2.32 & 16 & 1.05 & 0.49 \\
\hline Month 6 & 28 & 2.57 & 27 & 1.99 & 0.07 \\
\hline Month 7 & 17 & 1.52 & 19 & 1.30 & -0.09 \\
\hline Month 8 & 20 & 1.53 & 15 & 1.16 & 0.25 \\
\hline Month 9 & 20 & 1.85 & 20 & 1.55 & -0.03 \\
\hline Month 10 & 7 & 0.57 & 10 & 0.77 & -0.17 \\
\hline Month 11 & 24 & 1.92 & 10 & 0.67 & 0.74 \\
\hline Month 12 & 19 & 1.56 & 11 & 0.83 & 0.41 \\
\hline
\end{tabular}




\section{TABLE 2 Daily Size-Adjusted Returns Surrounding Insider Option Exercises}

Calendar time series means and t-statistics for daily size-adjusted returns on event portfolios. Each event portfolio is rebalanced daily to hold all firms in the indicated event period. An event at a firm is a day on which at least one insider exercises an option. The table summarizes time series from two different regulatory regimes. Prior to May 1991, the SEC required insiders to hold shares acquired through exercise for six months. In May 1991, the SEC removed this restriction.

\begin{tabular}{lccccc}
\hline & \multicolumn{2}{c}{ Jan 1984 to Dec 1990} & \multicolumn{2}{c}{ Jan 1992 to Nov 1995} & t-statistic for difference \\
Event period & Mean (bp) & t-statistic & Mean (bp) & t-statistic & in regime means \\
\hline Day -20 & 6 & 4.39 & 15 & 9.43 & -4.25 \\
Day -19 & 6 & 4.22 & 14 & 8.95 & -4.20 \\
Day -18 & 8 & 5.79 & 15 & 10.07 & -3.53 \\
Day -17 & 8 & 6.15 & 13 & 8.40 & -2.22 \\
Day -16 & 8 & 6.10 & 13 & 8.25 & -2.56 \\
Day -15 & 8 & 5.78 & 14 & 9.23 & -2.98 \\
Day -14 & 9 & 5.84 & 15 & 9.40 & -2.88 \\
Day -13 & 7 & 5.10 & 18 & 10.97 & -5.32 \\
Day -12 & 9 & 6.35 & 15 & 9.23 & -2.79 \\
Day -11 & 9 & 6.48 & 17 & 11.19 & -3.82 \\
Day -10 & 7 & 5.11 & 18 & 12.02 & -5.44 \\
Day -9 & 11 & 7.72 & 18 & 11.28 & -3.46 \\
Day -8 & 11 & 7.48 & 18 & 12.03 & -3.68 \\
Day -7 & 7 & 5.01 & 17 & 10.39 & -4.73 \\
Day -6 & 10 & 7.36 & 20 & 12.55 & -4.74 \\
Day -5 & 7 & 5.53 & 20 & 12.71 & -6.39 \\
Day -4 & 12 & 8.13 & 24 & 15.06 & -5.74 \\
Day -3 & 11 & 7.68 & 26 & 15.53 & -6.66 \\
Day -2 & 12 & 8.02 & 30 & 18.33 & -8.59 \\
Day -1 & 13 & 8.83 & 30 & 17.60 & -7.24 \\
Day 0 & 3 & 2.30 & 19 & 10.58 & -6.79 \\
\hline & & & & & \\
\hline
\end{tabular}


TABLE 2 (Continued)

\begin{tabular}{|c|c|c|c|c|c|}
\hline Event period & $\begin{array}{l}\text { Jan } 1984 \text { to } \\
\text { Mean (bp) }\end{array}$ & $\begin{array}{l}\text { Dec } 1990 \\
\text { t-statistic }\end{array}$ & $\begin{array}{l}\text { Jan } 1992 \text { to } \\
\text { Mean (bp) }\end{array}$ & $\begin{array}{l}\text { Nov } 1995 \\
\text { t-statistic }\end{array}$ & $\begin{array}{l}\text { t-statistic for difference } \\
\text { in regime means }\end{array}$ \\
\hline Days 1 to 20 & 4 & 7.31 & 4 & 4.64 & 0.22 \\
\hline Days 1 to 5 & 5 & 6.96 & 5 & 5.75 & 0.00 \\
\hline Days 6 to 10 & 3 & 3.94 & 3 & 2.96 & -0.09 \\
\hline Days 11 to 15 & 4 & 5.31 & 3 & 2.90 & 0.86 \\
\hline Days 16 to 20 & 2 & 2.90 & 3 & 3.60 & -1.09 \\
\hline Day 1 & 9 & 5.99 & 11 & 6.69 & -0.86 \\
\hline Day 2 & 5 & 3.32 & 5 & 3.11 & 0.14 \\
\hline Day 3 & 6 & 4.10 & 6 & 3.70 & 0.00 \\
\hline Day 4 & 4 & 2.75 & 2 & 1.48 & 0.62 \\
\hline Day 5 & 3 & 1.93 & 4 & 2.30 & -0.49 \\
\hline Day 6 & 3 & 2.02 & 3 & 1.62 & 0.12 \\
\hline Day 7 & 4 & 2.71 & 2 & 1.54 & 0.69 \\
\hline Day 8 & 3 & 2.45 & 2 & 1.58 & 0.44 \\
\hline Day 9 & 1 & 0.58 & 3 & 1.94 & -1.04 \\
\hline Day 10 & 3 & 1.96 & 2 & 1.45 & 0.19 \\
\hline Day 11 & 5 & 3.59 & 1 & 0.43 & 2.08 \\
\hline Day 12 & 3 & 2.12 & 5 & 3.24 & -1.09 \\
\hline Day 13 & 4 & 2.41 & 3 & 2.12 & 0.13 \\
\hline Day 14 & 5 & 4.01 & 3 & 1.64 & 1.44 \\
\hline Day 15 & 2 & 1.43 & 3 & 1.84 & -0.39 \\
\hline Day 16 & 3 & 2.01 & 3 & 1.90 & 0.00 \\
\hline Day 17 & 1 & 0.66 & 6 & 3.66 & -2.39 \\
\hline Day 18 & 2 & 1.68 & 3 & 1.82 & -0.28 \\
\hline Day 19 & 3 & 1.76 & 3 & 2.24 & -0.42 \\
\hline Day 20 & 2 & 1.29 & 3 & 1.73 & -0.37 \\
\hline
\end{tabular}




\section{TABLE 3 Monthly Size-Momentum-Adjusted Returns After Insider Option Exercises}

Calendar time series means and t-statistics for monthly size-momentum-adjusted returns on event portfolios. Each event portfolio is rebalanced monthly to hold all firms in the indicated event period. An event at a firm is a month in which at least one insider exercises an option. The table summarizes time series from two different regulatory regimes. Prior to May 1991, the SEC required insiders to hold shares acquired through exercise for six months. In May 1991, the SEC removed this restriction.

\begin{tabular}{lccccc}
\hline & \multicolumn{2}{c}{ Jan 1984 to Dec 1990 } & \multicolumn{2}{c}{ Jan 1992 to Nov 1995} & t-statistic for difference \\
Event period & Mean (bp) & t-statistic & Mean (bp) & t-statistic & in regime means \\
\hline Months 1 to 6 & 24 & 2.88 & 3 & 0.33 & 1.63 \\
Months 7 to 12 & 16 & 1.90 & 16 & 1.63 & -0.02 \\
Month 1 & 35 & 3.21 & 13 & 1.21 & 1.41 \\
Month 2 & 27 & 2.79 & -8 & -0.61 & 2.17 \\
Month 3 & 29 & 2.91 & 1 & 0.12 & 1.91 \\
Month 4 & 23 & 2.10 & -4 & -0.36 & 1.81 \\
Month 5 & 15 & 1.72 & 2 & 0.19 & 0.83 \\
Month 6 & 20 & 2.12 & 18 & 1.72 & 0.17 \\
Month 7 & 9 & 0.89 & 10 & 0.74 & -0.06 \\
Month 8 & 15 & 1.44 & 11 & 0.99 & 0.23 \\
Month 9 & 19 & 2.10 & 19 & 1.80 & 0.02 \\
Month 10 & 6 & 0.66 & 10 & 0.88 & -0.23 \\
Month 11 & 22 & 2.21 & 15 & 1.19 & 0.48 \\
Month 12 & 22 & 2.20 & 18 & 1.59 & 0.25 \\
\hline
\end{tabular}


TABLE 4 Daily Size-Momentum-Adjusted Returns After Insider Option Exercises

Calendar time series means and t-statistics for daily size-momentum-adjusted returns on event portfolios. Each event portfolio is rebalanced daily to hold all firms in the indicated event period. An event at a firm is a day on which at least one insider exercises an option. The table summarizes time series from two different regulatory regimes. Prior to May 1991, the SEC required insiders to hold shares acquired through exercise for six months. In May 1991, the SEC removed this restriction.

\begin{tabular}{|c|c|c|c|c|c|}
\hline Event period & $\begin{array}{l}\text { Jan } 1984 \text { t } \\
\text { Mean (bp) }\end{array}$ & $\begin{array}{l}\text { Dec } 1990 \\
\text { t-statistic }\end{array}$ & $\begin{array}{l}\text { Jan } 1992 \text { tc } \\
\text { Mean (bp) }\end{array}$ & $\begin{array}{l}\text { Nov } 1995 \\
\text { t-statistic }\end{array}$ & $\begin{array}{l}\text { t-statistic for difference } \\
\text { in regime means }\end{array}$ \\
\hline Days 1 to 20 & 2 & 5.14 & 1 & 1.01 & 2.23 \\
\hline Days 1 to 5 & 4 & 5.23 & 3 & 2.97 & 1.17 \\
\hline Days 6 to 10 & 1 & 2.05 & 0 & 0.21 & 1.08 \\
\hline Days 11 to 15 & 3 & 3.79 & 0 & -0.14 & 2.53 \\
\hline Days 16 to 20 & 1 & 1.69 & 1 & 0.83 & 0.41 \\
\hline Day 1 & 8 & 5.22 & 7 & 4.32 & 0.50 \\
\hline Day 2 & 4 & 2.74 & 2 & 1.38 & 0.91 \\
\hline Day 3 & 4 & 2.95 & 3 & 2.12 & 0.43 \\
\hline Day 4 & 2 & 1.33 & -1 & -0.67 & 1.37 \\
\hline Day 5 & 1 & 0.87 & 2 & 1.31 & -0.42 \\
\hline Day 6 & 1 & 0.75 & -2 & -1.12 & 1.33 \\
\hline Day 7 & 2 & 1.53 & 0 & 0.23 & 0.86 \\
\hline Day 8 & 2 & 1.64 & -1 & -0.45 & 1.44 \\
\hline Day 9 & -1 & -0.38 & 1 & 0.71 & -0.79 \\
\hline Day 10 & 1 & 0.71 & 0 & 0.12 & 0.39 \\
\hline Day 11 & 3 & 2.47 & -2 & -1.67 & 2.90 \\
\hline Day 12 & 2 & 1.23 & 3 & 1.80 & -0.56 \\
\hline Day 13 & 2 & 1.70 & -1 & -0.51 & 1.56 \\
\hline Day 14 & 4 & 3.05 & 1 & 0.42 & 1.75 \\
\hline Day 15 & 2 & 1.09 & 0 & -0.25 & 0.94 \\
\hline Day 16 & 2 & 1.15 & 0 & -0.17 & 0.92 \\
\hline Day 17 & 1 & 0.93 & 2 & 1.48 & -0.51 \\
\hline Day 18 & 1 & 0.64 & 0 & 0.23 & 0.25 \\
\hline Day 19 & 1 & 1.03 & 2 & 1.08 & -0.07 \\
\hline Day 20 & 0 & 0.29 & 0 & 0.01 & 0.20 \\
\hline
\end{tabular}


TABLE 5 Monthly Size-Momentum-Adjusted Returns in the Six Months After an Insider Exercise for Various Subsamples

Calendar time series means and t-statistics for monthly size-momentum-adjusted returns on event portfolios. Each event portfolio is rebalanced monthly to hold all firms with an event in the preceding six months. In the "Full sample," the event is a month with an insider exercise. The "Small firms," "Medium-sized firms," "Large firms," "Top managers," "Officers," "Directors," "Large shareholders," and "Top managers at small firms" subsamples restrict the sample according to firm size or insider position. "Non-dividend-related" exercises are those that do not fall between a dividend announcement date and an ex-dividend date. In the "Many insiders exercising" subsample, the event is a month in which the number of insiders exercising exceeds the average of that in the previous three months on the same quarterly cycle and which is neither a December nor January. The table summarizes time series from two different regulatory regimes. Prior to May 1991, the SEC required insiders to hold shares acquired through exercise for six months. In May 1991, the SEC removed this restriction.

\begin{tabular}{lccccc}
\hline & \multicolumn{2}{c}{ Jan 1984 to Dec 1990} & \multicolumn{2}{c}{ Jan 1992 to Nov 1995 } & t-statistic for difference \\
Subsample & Mean (bp) & t-statistic & Mean (bp) & t-statistic & in regime means \\
\hline Full sample & 24 & 2.88 & 3 & 0.33 & 1.63 \\
Small firms & 71 & 2.75 & -1 & -0.06 & 2.26 \\
Medium-sized firms & 34 & 2.74 & 3 & 0.20 & 1.66 \\
Large firms & 18 & 2.37 & 4 & 0.45 & 1.22 \\
Top managers & 31 & 3.05 & -2 & -0.16 & 2.15 \\
Officers & 27 & 3.08 & -1 & -0.13 & 2.06 \\
Directors & 25 & 2.17 & 14 & 0.93 & 0.56 \\
Large shareholders & 1 & 0.08 & 19 & 1.34 & -0.93 \\
Top managers at small firms & 120 & 2.19 & -87 & -2.45 & 3.17 \\
Non-dividend-related & 23 & 2.40 & 2 & 0.21 & 1.32 \\
Many insiders exercising & 26 & 2.89 & 0 & 0.03 & 1.87 \\
\hline
\end{tabular}




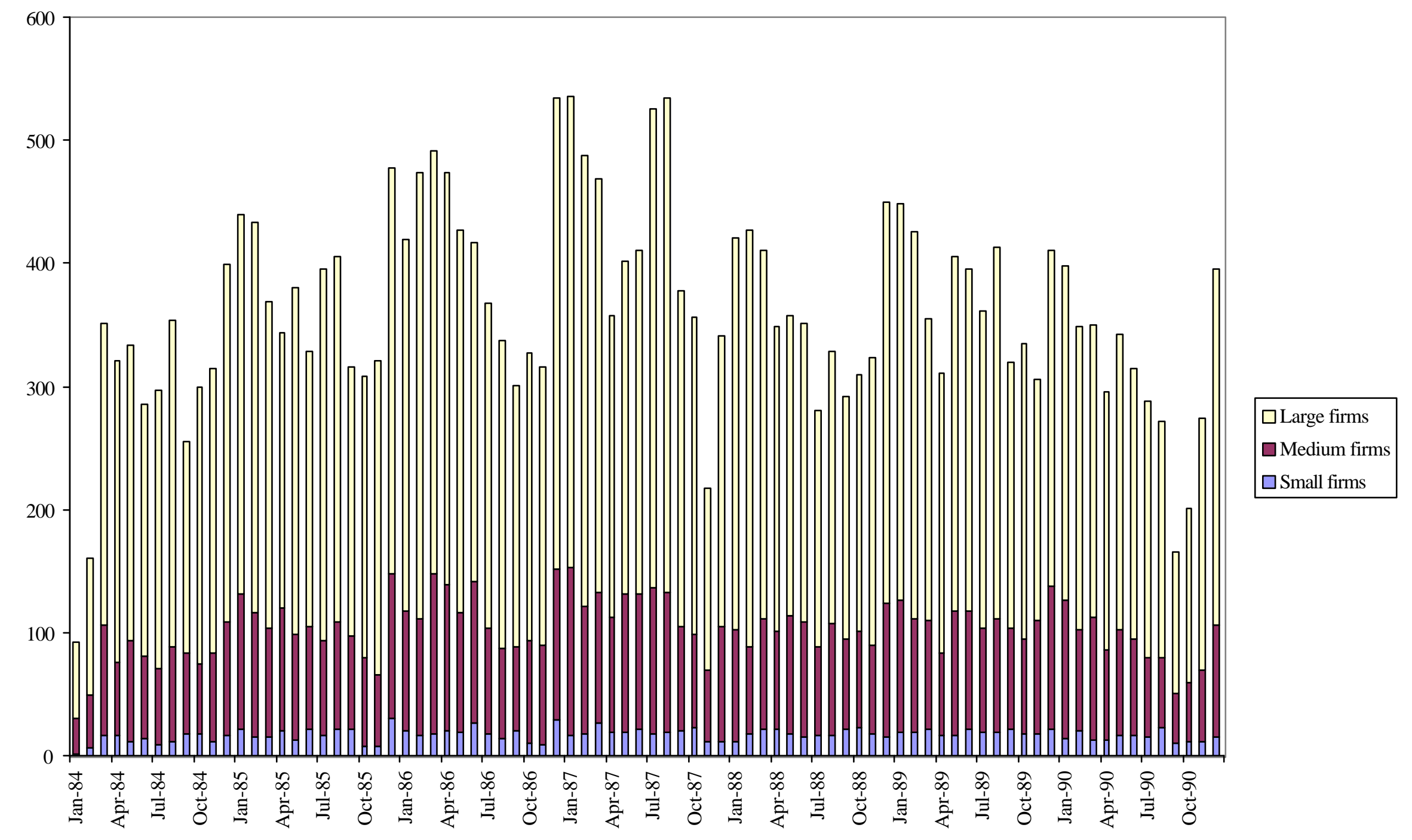

Fig. 1a. -- Number of firms with insider exercises, 1984-1990 


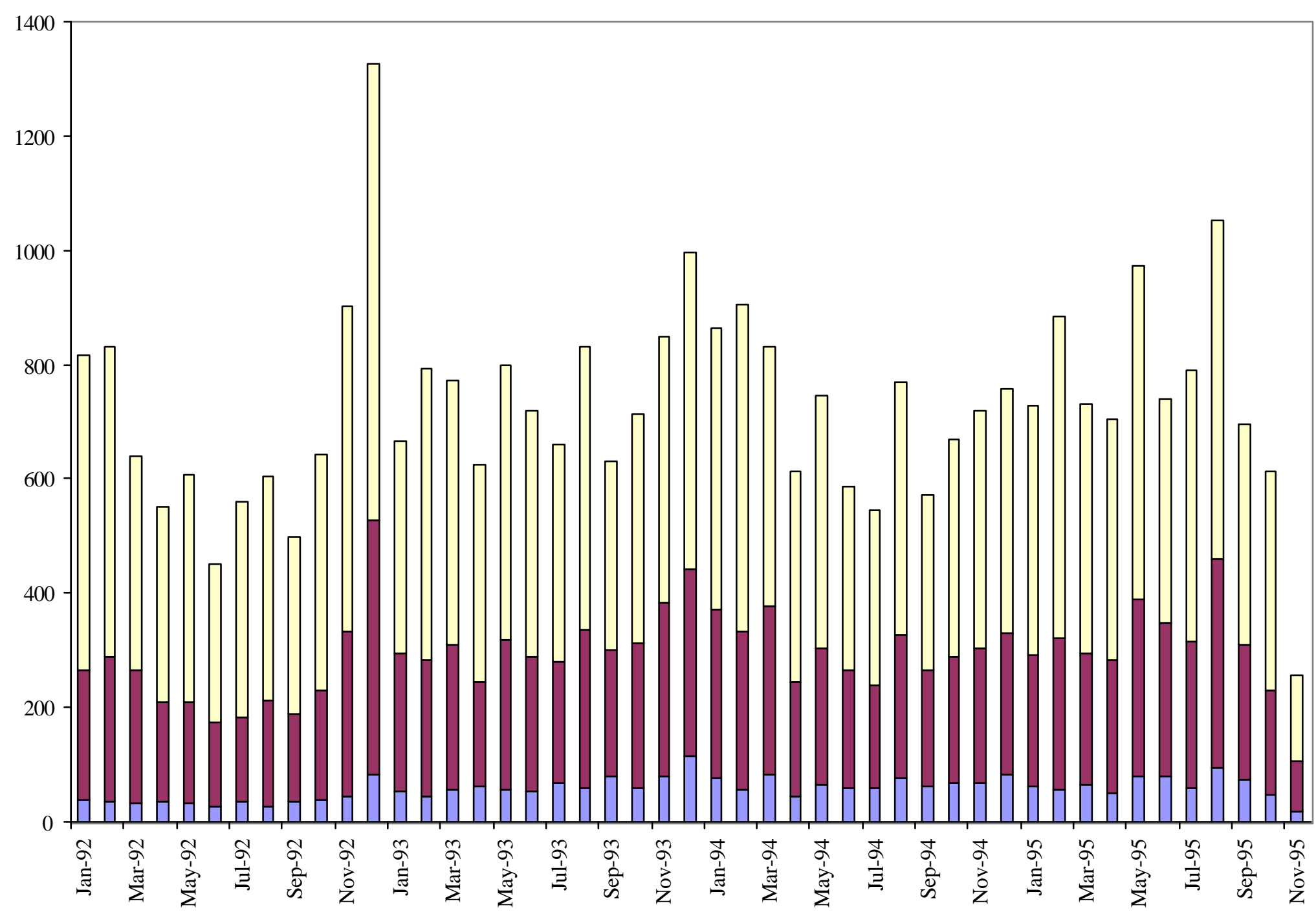

Fig. 1b. -- Number of firms with insider exercises, 1992-1995 


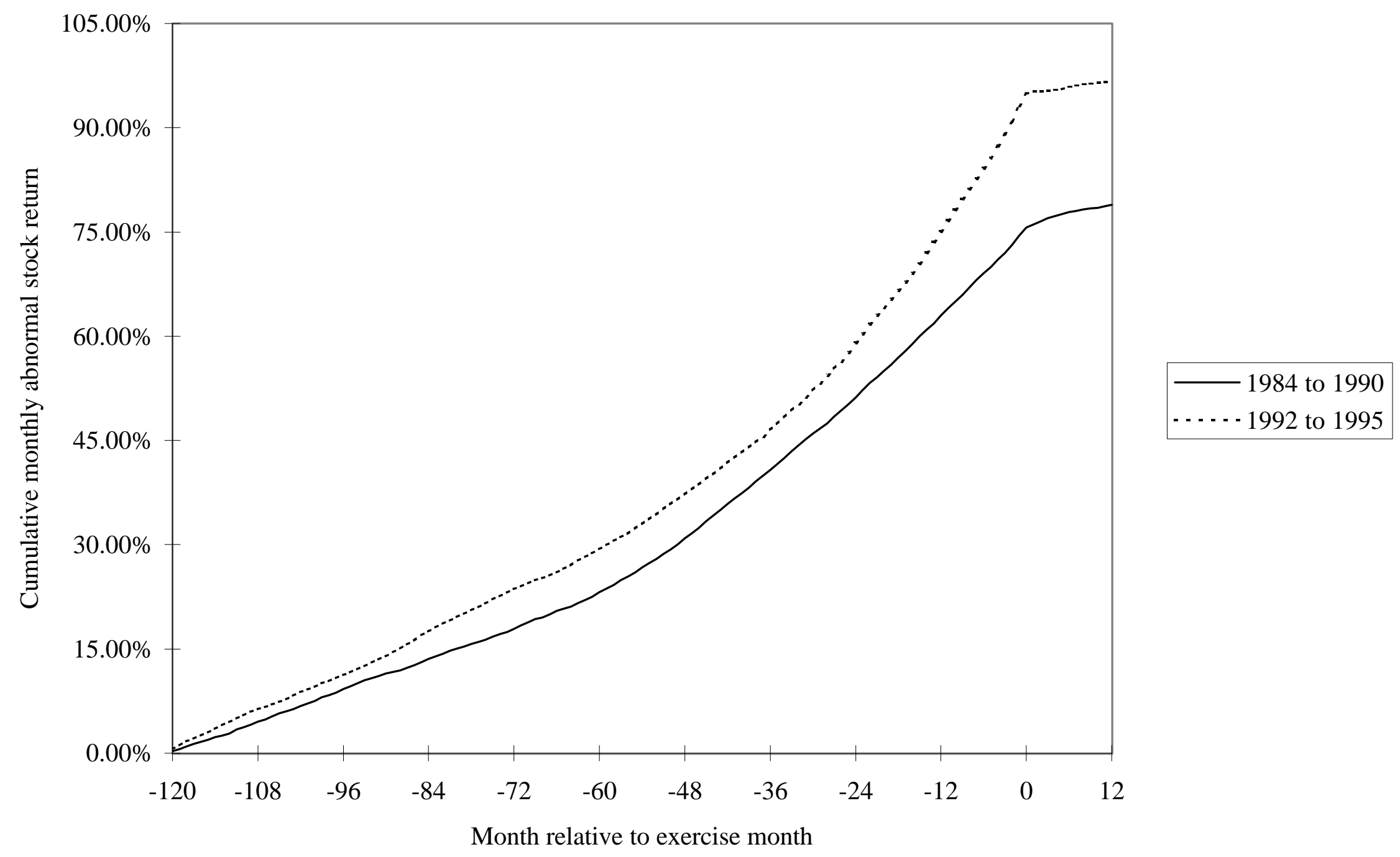

Fig. 2. -- Mean cumulative monthly size-adjusted stock returns around insider option exercises from two regulatory regimes. Prior to May 1991, the SEC required insiders to hold acquired shares for six months. 


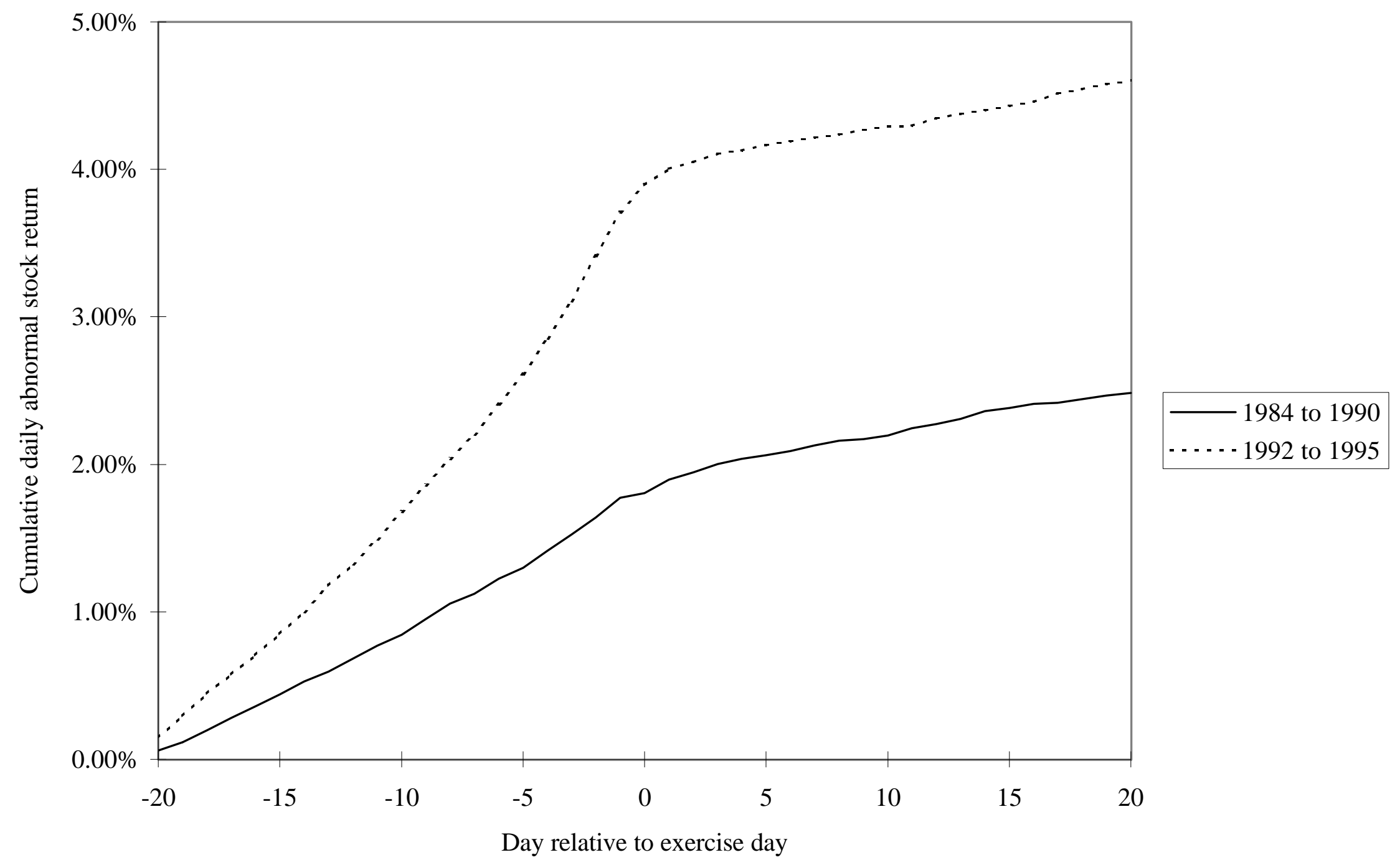

Fig. 3. -- Mean cumulative daily size-adjusted stock returns around insider option exercises from two regulatory regimes. Prior to May 1991, the SEC required insiders to hold acquired shares for six months. 